\title{
Cancer Incidence in Nigeria: A Tertiary Hospital Experience
}

\author{
Obiora Jude Uchendu
}

Delta State University, Abraka, Nigeria.

\begin{abstract}
Background: Cancer is a poorly addressed major cause of morbidity and mortality in Nigeria. Aim: The study aims at analyzing the age, gender and topography of cancer in Delta State, Nigeria. Setting: The research was conducted in the State tertiary health care center, the major referral center in Delta State, Nigeria. Materials and Methods: This is a 6-year (2014-2019) descriptive retrospective study of all histologically diagnosed cancer cases in the department of Histopathology, DELSUTH. Results: Cancer accounted for 668 (28.9\%) of the 2300 histologically diagnosed cases, involving 461 females and 207 males with mean ages of 48.40 and 54.14 respectively. The combined sex mean age and age range were 50.17 and 1-98 years respectively. The peak occurred in the $7^{\text {th }}$ decade for males and the $6^{\text {th }}$ decade for females. The most common cancers are breast $(36.5 \%)$, colorectal $(11.7 \%)$, prostate $(8.1 \%)$ cervical $(7.2)$, soft tissue $(6 \%)$, non-melanoma skin $(5.2 \%)$, ovarian $(4 \%)$, metastatic $(4 \%)$, gastric $(2.6 \%)$, thyroid $(1.8 \%)$, and salivary gland $(1.4 \%)$ cancers. The peak incidence for breast and thyroid cancers; lymphomas; colorectal and cervical cancers; ovarian; and prostate cancers occurred in the $4^{\text {th }}, 5^{\text {th }}, 6^{\text {th }}, 7^{\text {th }}$ and $8^{\text {th }}$ decades respectively. Conclusion: Cancer constitute a major disease burden, increases in incidence with age, and affects more females than males with breast, prostate, and colorectal cancers as most common cancers. Understanding the local epidemiological characteristic is fundamental to planning for proper preventive, diagnostic and therapeutic strategies.
\end{abstract}

Keywords: Cancer- disease- age- sex- site

Asian Pac J Cancer Care, 5 (1), 27-32

\section{Introduction}

Cancer is relatively common, accounting for the $2^{\text {nd }}$ most common cause of mortality after cardiovascular disease worldwide [1]. Across the globe, there were about 18.1 million new cancer cases and 9.6 million cancer deaths in 2018 [2]. In low and middle income countries reports show increasing rate of cancer, attributed to rapidly growing population, ageing population, westernized lifestyle and socioeconomic development [2]. Sadly, cancer fatality is also relatively high in these regions due to relatively low cancer awareness, late diagnosis, and lack of affordable curative services [3].

In Delta State of Nigeria, there is no previous study on the epidemiology of all cancers. The current study hopes to provide a hospital-based report on the age, gender and organ variation of cancer in this region. Such information will be vital in policy making, public health action and in providing a reference material for other researchers.
Submission Date: 11/11/2019 Acceptance Date: 01/06/2020

\section{Materials and Methods}

Delta State, Nigeria is an oil-rich State in Niger-Delta region of Nigeria. It currently has two tertiary care health facilities, and several government and private hospitals operating at lower levels of care.

There is currently no functional cancer registry within the state. As a result, histopathology department occupies a central position as the most reliable source for data for cancer cases.

The present study is a 6 years descriptive retrospective study of cancer cases diagnosed at the department of Histopathology of the Delta State University Teaching Hospital, Delta State (DELSUTH). Because the State has only two government histopathology laboratories, DELSUTH laboratory receives surgical specimens, not only from DELSUTH but from other hospitals operating within and around the state.

Information for this study was retrieved from copies of 
the patient's laboratory results within the departmental archives, and includes the age, gender, site/organ of lesion and histological diagnosis. Data analysis was with 2007 Excel Spread Sheet and the summary presented in tables.

Twenty-six cases with inconclusive diagnosis or missing results were encountered during the study, and excluded from the study. Ethical clearance was obtained from the institution (approval number: HREC/ PAN/2019/063/0345) before the study was commenced.

\section{Results}

A total of 668 cancer cases, representing $28.9 \%$ of all surgical specimens were received at the Histopathology department of DELSUTH during the study period. These consists of 207 males and 461 females, giving a male to female ratio of $1: 2.2$. The age range of cancer patients were 1-98 years while the mean age was 50.17 years. The gender-specific mean ages were for 54.14 for males and 48.40 for females.

Table 1 shows the age and gender distribution of cancer cases. The peak age for the male gender were in the $7^{\text {th }}$ decade; while the peak age for both the females and the combination of both gender were in the $6^{\text {th }}$ decades.

Table 2 shows the site distribution of cancer for both genders. The more common sites are breast $(36.5 \%)$, colorectum $(11.7 \%)$, prostate $(8.1 \%)$ cervix $(7.2)$, soft tissue $(6 \%)$, non-melanoma skin cancer $(5.2 \%)$, ovarian $(4 \%)$, metastasis $(4 \%)$,stomach $(2.6 \%)$, thyroid $(1.8 \%)$, and salivary gland (1.4\%).

Table 3 shows the distribution of cancer among males. The 207 cases encountered were distributed through prostate cancer $(26.1 \%)$, colon and rectum cancer $(17.4 \%)$, soft tissue cancer $(9.7 \%)$, non-melanoma skin cancer (8.7\%), non-hodgkins lymphoma (4.4\%),breast cancer (3.9\%),nasopharyngeal cancer $(3.9 \%)$ and stomach cancer $(3.9 \%)$.

Details of distribution of cancer among females is shown in Table 4 . The 461 cases were attributed mainly to breast cancer $(51.2 \%)$, cervical cancer $(10.4 \%)$, colon and rectal cancer $(9.1 \%)$, ovarian cancer $(5.9 \%)$, soft tissue $(4.3 \%)$, metastatic tumours $(4.3 \%)$, non-melanoma skin cancer $(3.7 \%)$, stomach $(2.0 \%)$, thyroid $(1.7 \%)$ and uterine cancer $(1.7 \%)$.

Table 1. Age and Gender Distribution of Cancer

\begin{tabular}{lcccc}
\hline Age range (years) & Males & Females & No of cases & Percentage \\
\hline $0-9$ & 11 & 5 & 16 & $2.4 \%$ \\
$10-19$ & 4 & 2 & 6 & 0.9 \\
$20-29$ & 7 & 20 & 27 & 4 \\
$30-39$ & 20 & 106 & 126 & 18.9 \\
$40-49$ & 25 & 98 & 123 & 18.4 \\
$50-59$ & 45 & 122 & 167 & 25 \\
$60-69$ & 50 & 78 & 128 & 19.2 \\
$70-79$ & 35 & 21 & 56 & 8.4 \\
$80-89$ & 10 & 7 & 17 & 2.6 \\
$90-99$ & 1 & 1 & 2 & 0.3 \\
Total & & & 668 & 100 \\
\hline
\end{tabular}

Table 2. Cancer Cases by Site/Organ

\begin{tabular}{|c|c|c|c|}
\hline Cancer site & Total & Percentage & Mean \\
\hline Anal cancer & 2 & 3 & 59 \\
\hline Bladder cancer & 5 & .8 & 50.2 \\
\hline Bone cancer & 2 & .3 & 40.5 \\
\hline Brain \& nervous system cancer & 7 & 1.1 & 49 \\
\hline Breast cancer & 244 & 36.5 & 48.14 \\
\hline Cervical cancer & 48 & 7.2 & 52.83 \\
\hline Colon \& rectal cancer & 78 & 11.7 & 52.63 \\
\hline Eye cancer & 1 & .2 & 2 \\
\hline Hodgkins lymphoma & 1 & .2 & 69 \\
\hline Kidney cancer & 6 & .9 & 21.33 \\
\hline Larynx cancer & 1 & .2 & 56 \\
\hline Lips and oral cavity & 3 & .5 & 47.33 \\
\hline Liver cancer & 1 & .2 & 2 \\
\hline Metastasis (L/N,Omentum,peritoneum) & 27 & 4 & 50.67 \\
\hline Nasopharyngeal cancer & 8 & 1.2 & 46.13 \\
\hline Non-Hodgkins lymphoma & 14 & 2.1 & 50.21 \\
\hline Oesophageal cancer & 6 & 0.9 & 59 \\
\hline Ovarian cancer & 27 & 4 & 47.15 \\
\hline Pancreatic cancer & 1 & .2 & 71 \\
\hline Prostate cancer & 54 & 8.1 & 68.65 \\
\hline Salivary gland cancer & 9 & 1.4 & 44.77 \\
\hline Skin cancer & 39 & 5.8 & 47.49 \\
\hline Small intestine cancer & 6 & .9 & 53.83 \\
\hline Soft tissue cancer & 40 & 6 & 39.7 \\
\hline Stomach cancer & 17 & 2.6 & 56.24 \\
\hline Testicular cancer & 1 & .2 & 1 \\
\hline Thyroid cancer & 12 & 1.8 & 36.33 \\
\hline Uterine cancer & 8 & 1,2 & 57 \\
\hline Total & 668 & 100 & 50.19 \\
\hline
\end{tabular}

Table 5 shows the age of the 10 most common malignancies in this study. No case of breast, colorectal, prostate, cervical, gastric and thyroid cancer was encountered in the first two decades. The peak incidence for breast and thyroid cancers; lymphomas; colorectal and cervical cancers; ovarian; and prostate cancers occurred in the $4^{\text {th }}, 5^{\text {th }}, 6^{\text {th }}, 7^{\text {th }}$ and $8^{\text {th }}$ decades respectively.

Details of the position by incidence of the 10 leading cancers were compared with other reports in Nigeria in Table 6

\section{Discussion}

Cancer is major public health challenge worldwide. With significant improvement in management of cardiovascular diseases, as well as population aging, cancer is bound to become the number one killer across the globe soonest [2]. Its incidence however has shown great variation across various countries, and over time, attributed to differences in socioeconomic, environmental and lifestyle factors [2-4]. There is therefore need to understand the peculiarity in each region, for effective planning and optimal utilization of scarce resources.

In this study, cancer accounted for $29 \%$ of surgical specimens received in the department. This is higher than 
Table 3. Male Cancer Cases by Site

\begin{tabular}{|c|c|c|c|}
\hline Site distribution of cancer case & Number of cancer & Percentage & Mean \\
\hline Bladder cancer & 2 & 1.0 & 64 \\
\hline Bone cancer & 1 & 0.5 & 16 \\
\hline Brain \& nervous system cancer & 5 & 2.4 & 43.8 \\
\hline Breast cancer & 8 & 3.9 & 61.63 \\
\hline Colon \& rectal cancer & 36 & 17.4 & 53.81 \\
\hline Eye cancer & 1 & 0.5 & 2 \\
\hline Kidney cancer & 5 & 2.4 & 14.8 \\
\hline Lips and oral cavity & 3 & 1.5 & 47.33 \\
\hline Liver cancer & 1 & 0.5 & 2 \\
\hline Metastasis & 7 & 3.4 & 48.29 \\
\hline Nasopharyngeal cancer & 8 & 3.9 & 46.13 \\
\hline Non-Hodgkins lymphoma & 9 & 4.4 & 50.56 \\
\hline Oesophageal cancer & 5 & 2.4 & 59.6 \\
\hline Pancreatic cancer & 1 & 0.5 & 71 \\
\hline Prostate cancer & 54 & 26.1 & 68.65 \\
\hline Salivary gland cancer & 4 & 1.9 & 55.5 \\
\hline Skin cancer & 21 & 10.2 & 52.17 \\
\hline Small intestine cancer & 3 & 1.5 & 44.33 \\
\hline Soft tissue cancer & 20 & 9.7 & 43.3 \\
\hline Stomach cancer & 8 & 3.9 & 52.38 \\
\hline Testicular cancer & 1 & 0.5 & 1 \\
\hline Thyroid cancer & 4 & 1.9 & 37.25 \\
\hline Total & 207 & 100 & 54.14 \\
\hline
\end{tabular}

$13.7 \%, 14.6 \%$, and $22.4 \%$ reported in Kano [5], Jos [6] and Akwa Ibom [7] respectively. Regrettably, surgical specimens submitted to histopathology department for evaluation are dominated by specimens considered as likely to be malignant, a practice seen across all levels of care within Nigeria [7]. There is need to continually educate the clinician on the need to send all resected specimen to surgical pathology laboratory for histopathological evaluation.

The study showed a decline in cancer incidence in the $2^{\text {nd }}$ decade, and subsequent rise with a peak in the $6^{\text {th }}$ decade and subsequent decline to lowest incidence in the $10^{\text {th }}$ decade. Notably $81.5 \%$ of the cancer occurred between the ages of 30-70 years, while being relatively rare in the first 2 decades. The peak incidence in our study corresponded with the peak observed in other centers in Nigeria [7-8] and in Quarter [9] but a decade lower than the peak noted in Ghana [10] and Ethiopia [11]. This reflects the close relationship between ageing and oncogenesis in a relatively young population structure with an average life expectancy of 53 years [12-13].

We observed a wide gender discrepancy in the distribution of cancer in this study with a male to female ratio of $1: 2.2$, a view upheld by all Nigerian investigators [5-6-7-8-14]. In contrast, however, cancer were higher among males in Ghana [10], United States of America, [15] India, [16] and Gabon [17]. It is obvious that in most secondary and tertiary care centers in Nigeria, the general and gynecologic surgery is well developed, accounting for high number of breast and gynecologic surgeries, which has polarized the gender-specific cancer incidence. Secondly, both the female breast and the uterine cervix are exposed organs, as a result of which related lesion are easily observed by these patients, with relatively increased number of clinical consultations for such cases. This study also highlighted the difference in average age of cancers cases in both genders.

The mean age for cancer diagnosis in males (54.14) was about half a decade higher than in females (48.14). This was also observed in other parts of the country, namely Akwa Ibom (males-59.63; females 45.69); [5] Sokoto (males-45.77;females-43.18); [8] Abuja (Males-49.1; females-45.4); [18] and Ibadan (males-51.1; females-49.1) [18]. This may be attributed to effect of reproductive hormones which tend to influence rapid cellular proliferation and oncogenic potential at a relatively younger age [19].

The ten favored sites for cancer in descending order in this study (excluding metastatic diseases) are breast, colon and rectum, prostate, cervix, skin, ovary, stomach, lymphoid organs, thyroid and salivary gland. In some European countries and United State of America, the most common cancer in both genders is lung, breast, prostate, colorectum and urinary bladder while in West Asia and North Africa, the lung, breast, colorectum, urinary bladder, and stomach topped the list [19]. In Nigerian studies, the heterogeneity in cancer incidence is very marked although there is general agreement that prostate cancer is the most 
Table 4. Female Cancer Cases by Site

\begin{tabular}{lccc}
\hline Site distribution of cancer cases & No of cases & Percentage of cases & Mean \\
\hline Anal cancer & 2 & 0.4 & 59 \\
Bladder cancer & 3 & 0.7 & 41 \\
Bone cancer & 1 & 0.2 & 65 \\
Brain \& nervous system cancer & 2 & 0.4 & 62 \\
Breast cancer & 236 & 51.2 & 47.68 \\
Cervical cancer & 48 & 10.4 & 52.83 \\
Colon \& rectal cancer & 42 & 9.1 & 51.62 \\
Hodgkins lymphoma & 1 & 0.2 & 69 \\
Kidney cancer & 1 & 0.2 & 54 \\
Larynx cancer & 1 & 0.2 & 56 \\
Metastasis (L/N,Omentum,peritoneum) & 20 & 4.3 & 51.3 \\
Skin cancer & 18 & 3.7 & 42.53 \\
Non-Hodgkins lymphoma & 5 & 1.3 & 49.6 \\
Oesophageal cancer & 1 & 56 \\
Ovarian cancer & 27 & 0.2 & 56 \\
Salivary gland cancer & 5 & 5.9 & 47.15 \\
Small intestine cancer & 3 & 1.1 & 36.2 \\
Soft tissue cancer & 20 & 0.7 & 63.33 \\
Stomach cancer & 9 & 4.3 & 36.1 \\
Thyroid cancer & 8 & 2.0 & 59.67 \\
Uterine cancer & 81 & 1.7 & 35.88 \\
Total & & 1.7 & 57
\end{tabular}

common cancer in men; breast and cervical cancer are the most common among females, and that lung cancer is uncommon [5-7-8-14-20-21-22-23].

There is obviously marked variation across countries and even within countries due to variation in risk factors, degree of economic development, population structure as well as genetic susceptibility [2].

Breast cancer was the most common cancer in this study, accounting for $36.5 \%$ of all cases which is the highest recorded in the country [5-7-8-14-21-23]. Across the globe, breast cancer is the $2^{\text {nd }}$ most commonly diagnosed malignant disease, accounting for $11.6 \%$ of all cases, with about 2.1 million new cases recorded in 2018 [2]. The mean age for breast cancer among females in this study is 47.68 years which correlates with other Nigerian studies [7-8] but lower than the mean age for Caucasians (61year) and Hispanics (56 years) [24]. The lower mean among the African population may be explained by the younger population structure [13]. Being an exposed organ, diseases of the breast easily attracts attention, hence the relatively high rate.

Colorectal cancer is the second most common cancer in this study but has the highest incidence among all Nigerian studies [5-7-8-14-20-21-23]. Worldwide, 1.8 million new cases were encountered in 2018 , amounting to $6.1 \%$ and ranking $3^{\text {rd }}$ among all cancers [2]. The relatively high incidence of colorectal cancer in this region may be related to genetic factors, and native diet rich in starch and oil (banga soup). This however calls for further research.

Prostate cancer is the most common cancer among males, accounted for $26.1 \%$ of male cancers in this study. This correlates with other Nigerian reports with the exception of observation in Ilorin, where hepatocellular cancer is encountered most often [5-7-8-14-20-21-22-23]. Worldwide, it is ranked second to lung cancer, with 1.3 million new cases recorded in 2018. As in our study, it is the most common cancer among males in US, Europe and Australia and most other Sub-Saharan African countries [2]. Reports has however shown relatively low incidence of prostate cancer in Asia, and North Africa possibly due to hereditary factors [25].

Cervical cancer is the $4^{\text {th }}$ most common cancer in this study, accounting for $7.2 \%$ of all cases among both sex, and $10.4 \%$ of all female cancers. There is a general consensus that it is the second most common cancer after breast cancer, except for Omonisis et al who reported that it is the leading female cancer [5-7-8-14-20-2122-23]. Report across the globe showed a decline in cervical cancer rate, accounting for $3.2 \%$ of new cancer cases in 2018. The decline has been predominantly in developed countries with most cervical cancer coming from Africa [2]. The difference is the result of adoption of population-based preventive strategies such as cervical screening and HPV vaccination in developed countries and lack of such in developing countries such as ours.

Soft tissue tumours are the $5^{\text {th }}$ most common cancer, accounting for $6.3 \%$ of cases in this investigation. They are highly heterogeneous with poorly understood etiology. Local reports has shown it is relatively common accounting for $2.4 \%-11.3 \%$ of Nigerian hospital cases 
Table 5. Frequency of Distribution of Top 10 Cancers by Age and Organ/Site

\begin{tabular}{lccccccccccc}
\hline Site & $0-9$ & $10-19$ & $20-29$ & $30-39$ & $40-49$ & $50-59$ & $60-69$ & $70-79$ & $80-89$ & $90-99$ & Total \\
\hline Breast & & & 3 & 68 & 63 & 63 & 34 & 11 & 2 & $244(36.5 \%)$ \\
Colorectum & & & 5 & 11 & 13 & 22 & 19 & 4 & 3 & 1 & $78(11.7 \%)$ \\
Prostate & & & & & 1 & 11 & 15 & 20 & 8 & $54(8.1 \%)$ \\
Cervix & & & & 9 & 8 & 15 & 13 & 2 & 1 & $48(7.2 \%)$ \\
Soft tissue & 6 & 2 & 4 & 8 & 3 & 8 & 6 & 3 & & $40(6 \%)$ \\
SKIN & & 1 & 6 & 6 & 7 & 6 & 6 & 6 & & 1 & $39(5.8 \%)$ \\
Ovarian & 1 & 2 & 1 & 3 & 7 & 4 & 8 & 1 & & $27(4 \%)$ \\
Stomach & & & & 1 & 4 & 5 & 4 & 2 & 1 & $17(2.6 \%)$ \\
Lymphoma & 1 & & 1 & 2 & 1 & 3 & 6 & 1 & & $15(2.3 \%)$ \\
Thyroid & & & 3 & 5 & 1 & 3 & & & & $12(1.8 \%)$ \\
\hline
\end{tabular}

Table 6. Frequency Distribution of Top 10 Cancers by Age and Organ/Site

\begin{tabular}{lccccccccc}
\hline Cancer site & Index Study & A & B & C & D & E & F & G & H \\
\hline Breast & 1 & 1 & 1 & 1 & 1 & 1 & 2 & 1 & 1 \\
Colo-rectum & 2 & 7 & 6 & NA & 7 & 7 & 6 & 5 & 5 \\
Prostate & 3 & 3 & 2 & 3 & 3 & 5 & 3 & 3 & 4 \\
Cervix & 4 & 2 & 3 & 2 & 6 & 2 & 1 & 2 & 2 \\
Soft tissue & 5 & 10 & 5 & 5 & 4 & NA & NA & 6 & NA \\
Skin & 6 & 5 & 4 & 4 & 6 & NA & 4 & 4 & NA \\
Ovarian & 7 & 8 & 8 & NA & NA & NA & NA & NA & 8 \\
Stomach & 8 & NA & NA & NA & NA & 10 & 5 & NA & 7 \\
Lymphoma & 9 & 4 & 7 & NA & NA & 4 & 7 & NA & 6 \\
Thyroid & 10 & NA & NA & NA & NA & NA & NA & NA & NA \\
\hline
\end{tabular}

\section{[5-7-26-27-28-29].}

Skin cancer was the 6 th most common cancer in this series. This accounted for $5.8 \%$ of cancer cases in this study. The risk factors for skin cancer are exposure to Ultra violet B radiation, and HIV epidemic which is associated with Kaposi sarcoma, both of which are prevalent in the study environment [2]. Our observation is comparable to reports from other Nigerian investigators [5-7-8-14-20-21-23].

Ovarian cancer was the $7^{\text {th }}$ most common cancer in the study, accounting for $4 \%$ of all cancers. It is however remains the $2^{\text {nd }}$ most common gynecological cancer after cervical cancer in Nigeria [5-7-8-14-21-23]. Unlike the cervical cancer, there is no pre-malignant stage and no screening tool yet, and therefore more common in developed countries than in Africa [2]. Across the globe, it accounted for $1.6 \%$ of all new cancers cases diagnosed in 2018 [2].

Stomach cancer is the $8^{\text {th }}$ most common cancer in this study, accounting for $2.6 \%$ of all histologically diagnosed cancers. Our observation is however higher than $1.2-1.9 \%$ reported in other parts of Nigeria [5-21-30$31]$. Worldwide, it is the 6th most common cancer with $1,033,700$ cases, accounting for $5.7 \%$ of all new cancer cases were recorded in 2018. There is also marked regional variation with highest incidence being in Far East (China and Japan) and the lowest being in Africa [2].

Lymphoma is the 9th most common cancer in this study, mostly of the Non-Hodgkins type and appear to be more common in Northern than in Southern Nigeria [5-7-8-14-20-21-22-23].

Thyroid cancer is the 10th most common cancer cases, with greater female predominance (M:F 1:2). Across the globe, 567000 new cases were diagnosed in 2018 . with MF ratio of $1: 3$. While exposure to environmental pollutants, obesity, smoking and hormonal exposure are suspected risk factors, the only well-established risk factor is exposure to ionizing radiation especially at childhood [32]. Available data show that it fell below $10^{\text {th }}$ position in all cancer data in Nigeria.

In summary, Cancer remains a poorly addressed public health problem with marked local and international variation in incidence. Studying its incidence in hospital will serve as an empirical guide till further evaluation is available. There is need for co-ordinated multi-institutional research to bridge this gap. There is also need for population-targeted cancer screening programme, cancer literacy, access to critical cancer diagnostic tools and treatment facility to ensure reduce its morbidity and mortality.

\section{Acknowledgements}

The author is indebted to staff and management of Delta State University Teaching Hospital, Oghara, Nigeria, and particularly to those of Histopathology department of the institution. 
Conflict of Interest

The author has no conflict of interest to declare.

\section{Author's contributions}

The work was done entirely by a single author.

\section{Source of funding}

Self.

\section{References}

1. GBD 2015 Mortality and Causes of Death Collaborators. Global, regional, and national life expectancy, all-cause mortality, and cause-specific mortality for 249 causes of death, 1980-2015: a systematic analysis for the Global Burden of Disease Study 2015. Lancet 2016;388: 1459-544

2. Bray F, Ferlay J, Soerjomataram I,Siegel RL, Torre LA, Jemal A.Global Cancer Statistics 2018: GLOBOCAN Estimates of Incidence and Mortality Worldwide for 36 Cancers in 185 Countries. CA CANCER J CLIN. 2018;0:1-31

3. Chalkidou K, Marquez P, Dhillon PK, et al. Evidenceinformed frameworks for cost-effective cancer care and prevention in low, middle, and high-income countries. Lancet Oncol. 2014; 15: 119-31

4. Ma X,Yu H. Cancer Epidemiology Global Burden of Cancer. Yale Journal of Biology and Medicine. 2006; 79: 85-94.

5. Yusuf I, Atanda AT, Umar AB, Imam MI, Mohammed AZ, Ochicha $\mathrm{O}$, et al. Cancer in Kano, Northwestern Nigeria: A 10-year update of the kano cancer registry. Ann Trop Pathol.2017;8:87-93.

6. Mandong BM, Madaki AK, Manasseh AN. Malignant diseases in Jos. Ann Afr Med 2003;2:49-53.

7. Nwafor CC, Nwafor NN. The pattern and distribution of cancers in Akwa Ibom State, Nigeria. Niger J Clin Pract 2018; 21: 603-8.

8. Sahabi SM. Abdullahi K Epidemiological Survey of Malignant Neoplasms in Sokoto,Nigeria. WJRR. 2017; 4(4):10-15.

9. Bener A, Ayub H, Kakil R, Ibrahim W. Patterns of cancer incidence among the population of Qatar: A worldwide comparative study. Asian Pac J Cancer Prev 2008; 9:19-24.

10. Laryea DO, Awuah B, Amoako YA, Osei-Bonsu E, Dogbe J, Larsen-Reindorf R, et al. Cancer incidence in Ghana, 2012: Evidence from a population-based cancer registry. BMC Cancer 2014; 14: 362

11. Tigeneh W, Molla A, Abreha A, Assefa M. Pattern of cancer in Tikur Anbessa specialized hospital oncology center in Ethiopia from 1998 to 2010. Int J Cancer Res Mol Mech 2015; $1: 1-5$

12. Aunan JR,Cho WC,Soreide K. The Biology of Aging and Cancer: A Brief Overview of Shared and Divergent Molecular Hallmarks.Aging Dis.2017;8(5):628-642.

13. Danjin M,Toyin MK,Tolulope ED. A Systematic Review of Life Expectancy Differences and the Disease Cycle as a Major Predictor in Africa: The Nigeria Scenarios. Open Access Journal of Nursing.2018;1(2):89-96.

14. Samaila MO, Ayeni EI, Ahmed SA. Cancer pattern in a hospital-based registry. Archives of International Surgery $.2015 ; 5(2) 57-62$.

15. Siegel, R. L., Miller, K. D. and Jemal, A. Cancer statistics, 2017. CA Cancer J.2017 Clin. 67, 7-30.

16. Rasool MT, Lone MM, Wani ML, Afroz F, Zaffar S, Mohib-ul Haq M, et al. Cancer in Kashmir, India: Burden and pattern of disease. J Cancer Res Ther. 2012; 8: 243-6.

17. Nze-Nguema F, Sankaranarayanan R, Barthelemy M, Nguizi-Ogoula S, Whelan S, Minko-Mi-Etoua D, et al.
Cancer in Gabon, 1984-1993: A pathology registry based relative frequency study. Bull Cancer 1996; 83: 693-6.

18. Jedy-Agba EE, Oga EA, Odutola M, Abdullahi YM, Popoola A, Achara P, Afolayan E, Banjo AA, Ekanem IO, Erinomo O, Ezeome E. Developing National Cancer Registration in Developing Countries-Case Study of the Nigerian National System of Cancer Registries. Frontiers in public health. 2015;3:186.

19. Mandong BM, Manasseh AN, Ayuba DM, Olugbenga SA, Emmanuel I, Kwaghe BV, Mandong JB. Burden of Cancer in Plateau State, Central Nigeria: A 27-year report from a tertiary hospital-based cancer registry. JAMMR.2018; 28(11):1-11.

20. Omonisi A, OlasodeB, KomolafeA, Omoniyi-Esan G, JedyAgbaE, OdesanmiW. Morphological Survey of Malignant Tumours in Ife-IjeshaSouthwestern Nigeria Results from the Ife-Ijesha Cancer Registry 1991-2010. NCRI Conference 2014.

21. Abiodun A,Olatunde I, Rakiya S. Situation analysis of cancer magnitude in a tertiary

health institution in Nigeria. International Journal of life science and Pharma research. 2012; 2(2):107-114.

22. Morounke SG, Ayorinde JB, Benedict AO, Adedayo FF, Adewale FO, et al. Epidemiology and Incidence of Common Cancers in Nigeria. J Cancer Biol Res.2017; 5(3): 1105.

23. Silas OA, Manasseh AN, Musa J, Dauda AM, Zoakah AI,Mandong BM, et al. Changing patterns in trend of top 10 cancers in the Jos University Teaching Hospital's (JUTH) cancer registry (1996-2018), Jos, north-central Nigeria. J Med Trop 2019; 21:81-6.

24. Kumar V, Abbas AK, Aster JC. The breast: In Robbins and Cotran pathologic basis of diseases 9 th ed. Elsevier Saunder. 2015; 1043-1071.

25. Taitt HE. Global Trends and Prostate Cancer: A Review of Incidence, Detection, and Mortality as Influenced by Race, Ethnicity, and Geographic Location. American Journal of Men's Health. 2018; 12(6):1807-1823.

26. Seleye-Fubara D, Nwosu SO, Yellowe BE. Soft tissue sarcomas in the Niger Delta Region of Nigeria (a referral hospital's study). Niger J Med 2005; 14:188-94.

27. Igun GO. The diagnostic evaluation and surgical management of soft tissue sarcoma. West Afr J Med. 1998; 17:232-5.

28. Mandong BM, Kidmas AT, Manasseh AN, Echejoh GO, Tanko MN, Madaki AJ. Epidemiology of soft tissue sarcomas in Jos, North Central Nigeria. Niger J Med. 2007; 16: 246-9

29. Yusuf I, Mohammed AZ, Iliyasu Y. Histopathological study of soft tissue sarcomas seen in a teaching hospital in Kano, Nigeria. Niger J Basic Clin Sci. 2013; 10:70-5

30. Ebili HO, Oluwasola AO, Akang EE, Ogunbiyi JO. Clinicopathological features of gastric carcinoma in Ibadan, Nigeria, 2000-2011. Niger Med J.2015; 56:126-31.

31. Abdulkareem FB, Faduyile FA, Daramola AO, Rotimi O, Banjo AA, Elesha SO, et al. Malignant gastrointestinal tumours in south western Nigeria: A histopathologic analysis of 713 cases. West Afr J Med. 2009; 28:173-6.

32. Kitahara CM, Schneider AB, Brenner AV. Thyroid cancer. In: Thun MJ, Linet MS,Cerhan JR, Haiman CA, Schottenfeld D,eds. Cancer Epidemiology and Prevention.4th ed. New York: Oxford University Press; 2018: 839-860.

This work is licensed under a Creative Commons AttributionNon Commercial 4.0 International License. 